\title{
Qualidade bacteriológica de queijos artesanais comercializados em estradas do litoral norte do Rio Grande do Sul, Brasil
}

\author{
Bacteriological quality of homemade cheeses commercialised in roads of the \\ northern coast of Rio Grande do Sul, Brazil
}

Cristina Bergman Zaffari ${ }^{\mathrm{I}}$ Jozi Fagundes Mello ${ }^{\mathrm{II}}$ Marisa da Costa ${ }^{\mathrm{III}}$

\section{RESUMO}

O consumo de queijo artesanal, vendido em estabelecimentos de beira de estrada, é comum no Estado do Rio Grande do Sul. Geralmente estes produtos não são fabricados em acordo com as boas normas de fabricação $e$ podem constituir perigo à saúde do consumidor. Objetivouse, com o presente trabalho, verificar a qualidade bacteriológica de queijos artesanais comercializados em estradas litorâneas por meio da contagem de coliformes $e$ pesquisa de Listeria spp. e Brucella spp. Foram analisados 80 queijos, sendo 62 do tipo Colonial, dez do tipo Provolone, seis do tipo Ricota e dois do tipo Caccio Cavallo. No momento da coleta, $71 \%$ das amostras não estavam sob refrigeração. Todas as amostras apresentaram contagens de coliformes totais e, destas, 62 foram testadas para a presença de coliformes fecais. Um total de $84 \%$ das amostras apresentou contagens de coliformes fecais acima de 2,73- 3,7 log.UFC $g^{-1}$ (de 500 a 5000UFC $\mathrm{mL}^{-1}$ ), previsto como limite máximo a ser encontrado em queijos. Dos 29 estabelecimentos, 27 tinham produtos fora destes limites. Das 80 amostras, 16\% continham Listeria spp., sendo 3,7\% identificadas como Listeria monocytogenes. As estações do ano influenciaram no isolamento de Listeria spp., sendo a primavera considerada a estação do ano com maior número de isolados. Brucella spp. não foram isoladas nas 80 amostras de queijos analisadas. A alta freqüência de coliformes fecais e a presença de $\mathbf{L}$. monocytogenes revelam que o consumo destes queijos constitui perigo de infecção à população em geral e especialmente àquelas pessoas imunocomprometidas.

Palavras-chave: Caccio Cavallo, Colonial, Provolone, Ricota, coliformes, Listeria monocytogenes, Brucella spp.

\section{ABSTRACT}

The consumption of homemade cheese, which is sold in little shops along the road, is very common in the state of Rio Grande do Sul, Brazil. Generally, these products are not manufactured according to the good hygiene guidelines; and may be a risk to the consumers' health. The aim of this research was the assessment of the bacteriological quality of homemade cheese sold in the region along the northern coast of Rio Grande do Sul. Cheese samples were taken and total and faecal coliform counting per gram sample were established. The samples were also examined for the presence of Listeria spp. and Brucella spp. In total, 80 samples, from 29 commercial establishments were analysed, of which 62 of Colonial type; 10, of Provolone; 6 of Ricotta and 2, of Cacciocavallo type. At the moment of sampling, $71 \%$ of them were not stored under refrigeration conditions. In all the samples the presence of total coliform could be demonstrated and 62 of these were tested for the presence of faecal coliforms. In $84 \%$ of the samples more then 2.73 - 3.7log.UFC $\mathrm{g}^{-1}$ (from 500 to 5000UFC $\mathrm{mL}^{-1}$ ) of faecal coliform could be demonstrated, with is considered the maximum limit still allowed to be present in cheese samples. Of the 29 establishments analysed, 27 had products with coliforms counts above these limits. Of the 80 samples, $16 \%$ had Listeria sp., of which $3.7 \%$ were identified as Listeria monocytogenes. A correlation was found between the season and the isolation of Listeria spp.: in the spring the highest number was detected. Brucella spp. could not be detected in the 80 samples analysed. The high frequency of faecal coliforms and the presence of $\boldsymbol{L}$. monocytogenes revealed that the consumption of these homemade cheeses can become a risk of infection to the population, especially for immunocompromised persons.

Key words: cacciocavallo, Colonial, Provolone, Ricota, coliforms, Listeria monocytogenes, Brucella spp.

\section{INTRODUÇÃO}

No Rio Grande do Sul, como na maioria dos Estados brasileiros, existe a tradição do consumo de produtos artesanais por serem considerados, pela

'Programa de Pós-graduação em Microbiologia Agrícola e do Ambiente, Faculdade de Agronomia, Universidade Federal do Rio Grande do Sul (UFRGS), Porto Alegre, RS, Brasil.

II Programa de Pós-graduação em Ciência e Tecnologia de Alimentos, Instituto de Ciências e Tecnologia de Alimentos, UFRGS, Porto Alegre, RS, Brasil.

III Departamento de Microbiologia, Instituto de Ciências Básicas da Saúde, UFRGS. Rua Sarmento Leite, 500, sala 158, 90050-170,

Porto Alegre, RS, Brasil. E-mail: mdcosta@ufrgs.br. Autor para correspondência. 
população, mais naturais e saborosos. Por outro lado, a venda destes produtos é uma das principais fontes de renda de pequenos produtores que os comercializam diretamente ao consumidor, geralmente em estabelecimentos à beira de estradas. Dentre os produtos artesanais mais apreciados está o queijo, cuja fabricação, como a de outros alimentos, necessita seguir normas rigorosas de higiene; além disso, a matéria prima deve originar-se de animais em condições sanitárias adequadas. Falhas no controle de qualidade tanto da matéria prima, quanto no seu beneficiamento e estocagem, podem resultar em um produto de má qualidade e em risco de infecções e intoxicações nos consumidores. Esses produtos artesanais podem conter microrganismos de origens diversas (animal, ambiente, homem), que podem causar doenças, resultar em alterações físico-químicas no produto, influenciar na eficiência dos processos utilizados no seu beneficiamento e nas suas características sensoriais. A maioria dos microrganismos presentes na matériaprima pode ser eliminada através da pasteurização que, em condições artesanais, pode não ser efetiva.

Entre os patógenos que podem ser encontrados no queijo estão a Listeria sp. e a Brucella sp. Existem poucos relatos de listeriose humana no Brasil, como também das fontes de contaminação. Apesar de atingir um grupo reduzido de pessoas, a listeriose é uma doença séria porque apresenta uma taxa de mortalidade entre 20 e 40\% (COSSART, 1992; MCLAUCHLIN et al., 2004). Essa alta taxa de mortalidade ocorre principalmente porque as pessoas infectadas geralmente apresentam algum tipo de deficiência imunológica. Uma média de 14 casos de internações anuais por listeriose tem ocorrido no país e, no Rio Grande do Sul, de 1,7 casos (DATASUS, 2005b). No Rio Grande do Sul, em um único hospital, foi detectada a presença de $\mathbf{L}$. monocytogenes pela técnica de imunohistoquímica em 33\% de placentas obtidas após aborto ou parto prematuro (SCHWAB \& EDELWEISS, 2003). Estes dados indicam que a infecção por $\mathbf{L}$. monocytogenes está presente e que as fontes de contaminações devem ser identificadas.

Os queijos são os produtos mais relacionados com contaminação da população por Brucella spp. em países que não utilizam leite pasteurizado em sua fabricação, sendo a Brucella melitensis a principal espécie envolvida. Embora esta espécie não tenha sido encontrada no Brasil, existem relatos de outras espécies de Brucella sp. presentes no leite e em queijos artesanais, o que constitui perigo para o consumidor (LANGONI et al., 2000, FREITAS et al., 2002). A brucelose humana também é relatada com pouca freqüência no Brasil e tem apresentado uma média de 17 internações anuais no país e uma no Rio Grande do Sul (DATASUS, 2005a). Apesar de os relatos mais recentes não terem sido relacionados com o consumo de queijos, este produto pode constituir uma fonte em potencial, se durante sua produção não forem observadas normas rigorosas de fabricação (SANTOSNETO et al., 1999, FERREIRA et al., 2002, FREITAS et al., 2002).

Assim, objetivou-se com o presente estudo investigar se os queijos artesanais comercializados na região litorânea norte do Estado do Rio Grande do Sul representam perigo à saúde dos consumidores, sendo que esta região recebe o maior número de turistas nos períodos de veraneio. Para isso, verificou-se a qualidade bacteriológica de queijos artesanais através da contagem de coliformes totais e fecais e da pesquisa de Listeria spp. e Brucella spp.

\section{MATERIAL E MÉTODOS}

Entre setembro de 2004 e junho de 2005, foram coletadas 80 amostras de queijos comercializados em 29 bancas localizadas nas estradas RS 30 (OsórioTramandaí), RS 40 (Viamão-Pinhal) e RS 389 (OsórioTorres). De cada banca, foram adquiridas uma ou mais amostras, coletadas aleatoriamente. Foram realizadas duas visitas, em diferentes períodos do ano, em cada estabelecimento. Foram realizadas 12 coletas, sendo cinco no verão, quatro na primavera e três no outono. As amostras foram transportadas em recipiente isotérmico contendo de gelo reciclável e mantidas sob refrigeração até o momento das análises. Antes das análises, foi removido assepticamente aproximadamente $1 \mathrm{~cm}$ de espessura da parte externa de cada queijo.

Para as análises bacteriológicas, 25 gramas da parte interna de cada amostra foram acondicionados em sacos plásticos esterilizados contendo 225mL da água peptonada 0,1\% (Merck - Alemanha). As amostras foram homogeneizadas e diluições decimais de $10^{-2} \mathrm{a}$ $10^{-4}$ foram utilizadas para a contagem de coliformes totais, coliformes fecais e isolamento de Brucella spp. Para o isolamento de Listeria spp., outros 25 gramas de queijo foram acondicionados em sacos plásticos esterilizados, contendo $225 \mathrm{~mL}$ de Caldo de 
Enriquecimento para Listeria (LEB - Difco - França) e homogeneizados durante 90 segundos.

Para a contagem de coliformes totais e fecais, alíquotas de $1 \mathrm{~mL}$ das diluições foram dissolvidas em 20mL de ágar vermelho violeta bile lactose (VRBA Merck - Alemanha), sendo adicionada uma sobrecamada do mesmo meio após solidificação. As placas foram incubadas a $37^{\circ} \mathrm{C}$ por 24 a 48 horas. Após este período, foram selecionadas as placas que apresentavam entre 25 e 250 unidades formadoras de colônias (UFC), sendo contadas aquelas com características de coliformes totais. A confirmação foi feita pela inoculação de 5 UFC, de cada placa, em caldo verde brilhante lactose bile 2\%) (Biobrás- Brasil). Foram considerados positivos os tubos que apresentaram presença de gás e turvação após 24-48 horas em banho de água a $37^{\circ} \mathrm{C}$. A contagem de coliformes fecais foi realizada semeando-se 5 UFC, provenientes do ágar VRBA, em caldo EC (Difco - EUA). Foram considerados positivos os tubos com turvação e presença de gás após 24 a 48 horas em banho de água a $45^{\circ} \mathrm{C}$. A contagem foi determinada através da proporção do número de colônias típicas contadas em VRBA e confirmadas em caldo EC pelo inverso da diluição, sendo o resultado expresso em log Unidades Formadoras de Colônia por grama (log.UFC/g) de queijo.

Para a detecção de Listeria sp., imediatamente após a diluição, alíquotas foram retiradas para esgotamento em ágar Oxford Modificado (MOX Difco - França) e ágar Palcam (PAL - Merck - Alemanha), incubadas durante 48 horas a $35^{\circ} \mathrm{C}$, sendo o caldo LEB incubado por sete dias em temperatura de $30^{\circ} \mathrm{C}$. Novas alíquotas deste caldo foram retiradas após 48 horas e 7 dias de incubação e semeadas em ágar MOX e PAL, sendo incubadas a $35^{\circ} \mathrm{C}$ por 48 horas. Colônias características em ambos os meios, MOX e PAL, foram isoladas em ágar triptona de soja contendo $0,6 \%$ de extrato de levedura e incubadas a $30^{\circ} \mathrm{C}$ por 24 horas. Após exame sob luz oblíqua, foram selecionadas as colônias típicas, que foram identificadas conforme MACFADDIN (2000) pelos testes: Gram, catalase, oxidação-fermentação glicose, motilidade $25^{\circ} \mathrm{C}$, CAMP TEST empregando Staphylococcus aureus e Rhodococcus equi, hemólise, fermentação de manitol, ramnose, xilose, produção de $\mathrm{H}_{2} \mathrm{~S}$ e redução de nitrato. Para o isolamento de Brucella spp. foi utilizada a diluição $10^{-4}$ de cada amostra preparada para a contagem de coliformes. Foram adicionados $200 \mu \mathrm{L}$ da diluição em $2 \mathrm{~mL}$ de caldo Brucella (caldo triptona de soja, $5 \%$ soro eqüino, polimixina $\mathrm{B}\left(5 \mathrm{U} \mathrm{L}^{-1}\right)$, bacitracina (25U L $\left.\mathrm{L}^{-1}\right)$, ácido nalidíxico $\left(5 \mathrm{mg} \mathrm{L}^{-1}\right)$, nistatina $\left(100 \mathrm{U} \mathrm{l}^{-1}\right)$ e ciclohexamida (100 $\left.\mathrm{mg} \mathrm{L}^{-1}\right)$. Os tubos permaneceram em temperatura de $37^{\circ} \mathrm{C}$ em microaerofilia. Após 48 horas, alíquotas foram semeadas em ágar Brucella (caldo Brucella, 1,5\% ágar-ágar) e incubadas a $37^{\circ} \mathrm{C}$ em microaerofilia durante sete dias ou mais. As colônias características de Brucella spp. foram re-isoladas em ágar soro (ágar triptona de soja, 5\% soro eqüino) e incubadas em temperatura de $37^{\circ} \mathrm{C}$ em microaerofilia. Colônias características foram isoladas e identificadas pelos testes: Gram, oxidase, oxidação-fermentação da glicose, crescimento MacConkey, catalase, dependência de $\mathrm{CO}_{2}$, produção de indol, $\mathrm{H}_{2} \mathrm{~S}$, redução de nitrato e produção de urease segundo Christensen (MACFADDIN, 2000; ALTON et al.,1988).

Os dados microbiológicos foram analisados utilizando valores em logaritmo. Foram realizadas análises da variância, Teste de t de Student, Turkey-HSD e Qui-quadrado, utilizando o programa SPSS/PC versão 8.0 (Statistical Package for the Social).

\section{RESULTADOS E DISCUSSÃO}

Das 80 amostras analisadas, 62 (78\%) foram de queijos do tipo Colonial, 10 (12\%) do tipo Provolone, 6 (7\%) do tipo Ricota e 2 (3\%) do tipo Caccio Cavallo. Destas amostras, no momento da coleta, 57 (71\%) não estavam sob refrigeração, enquanto 23 (29\%) estavam refrigeradas (Tabela 1 ).

Todas as amostras apresentaram contagem de coliformes totais, entre 3,18 e $\geq 6 \log$. UFC g ${ }^{-1}$. Das 80 amostras de queijo, 18 apresentaram contagens de coliformes totais superiores a $6 \log$.UFC g-1 na última diluição, impossibilitando o isolamento de colônias para confirmação de coliformes fecais. Nas 62 amostras restantes, foi observada a presença de coliformes fecais com contagens entre 2,77 e 5,81 log.UFC g ${ }^{-1}$ (Tabela 1), sendo que 52 amostras (84\%) apresentaram contagens acima de 2,73-3,7 log.UFC g-1 (de 500 a 5.000 UFC mL $^{-1}$ ), previsto como limite máximo de coliformes fecais em queijos (ANVISA, 2001).

Dos 29 estabelecimentos, 27 comercializavam queijos que apresentavam contagens de coliformes fecais acima dos valores estabelecidos na legislação vigente. Da análise desses resultados, pode-se inferir que a maioria dos queijos comercializados nestes estabelecimentos não apresenta condições sanitárias para consumo. Outros autores têm relatado a qualidade

Ciência Rural, v.37, n.3, mai-jun, 2007. 
Tabela 1 - Contagem de coliformes fecais em queijos coletados entre setembro de 2004 e junho de 2005, em estradas litorâneas do Rio Grande do Sul.

\begin{tabular}{lclc}
\hline Tipo queijo & $\mathrm{N}^{\mathrm{o}}$. amostras & Exposição & ${\text { Coliformes fecais }\left(\log . \text { ufc.g }^{-1}\right)^{*}}$ \\
\hline Colonial & 29 & Não refrigerados & $4,71(3,41-5,81)$ \\
Caccio cavalo & 02 & Não refrigerados & $3,58(3,08-4,08)$ \\
Provolone & 10 & Não refrigerados & $3,73(2,77-4,34)$ \\
Colonial & 16 & Refrigerados & $3,99(3,01-5,08)$ \\
Ricota & 05 & Refrigerados & $4,19(3,79-5,05)$ \\
\hline
\end{tabular}

*: média das leituras. Entre parênteses, valores mínimos e máximos encontrados.

insatisfatória destes produtos comercializados no país e destacado que não têm sido observadas melhoras neste sentido (ARAÚJO et al., 2001; LOGUERCIO \& ALEIXO, 2001; IDE \& BENEDET, 2001; FEITOSA et al., 2003).

Quando foram comparados os tipos de queijos verificou-se que, em relação à contagem de coliformes totais e fecais, houve diferença estatística $(\mathrm{P}<0,05)$ entre o Colonial e o Provolone. O Colonial apresentou maior média na contagem de coliformes fecais e totais em relação ao Provolone. O queijo tipo Ricota apresentou média de contagem superior ao Provolone, talvez pela maior umidade do primeiro, permitindo uma maior sobrevivência e multiplicação dos microrganismos. Entretanto, devido ao número de amostras analisadas, não foi possível assegurar a significância estatística.

Os queijos que se encontravam refrigerados no momento da coleta apresentaram média de contagem de coliformes totais e fecais inferiores aos nãorefrigerados, havendo diferença estatística $(\mathrm{P}<0,05)$ entre eles. Esse resultado era esperado, pois temperaturas baixas diminuem o metabolismo microbiano e conseqüentemente sua multiplicação. Já a estação do ano em que as amostras foram coletadas não influenciou na contagem de coliformes totais e fecais.

Das 80 amostras analisadas quanto à presença de Listeria spp., 13 (16\%) foram positivas. Estas amostras foram adquiridas de 11 bancas (38\%) das 29 coletadas. O perfil bioquímico dos 13 isolados está apresentado na Tabela 2. A presença de Listeria spp. é mais um indicativo de que os produtos analisados ou suas matérias-primas não foram submetidos aos procedimentos higiênico-sanitários e tecnológicos adequados. Foram isoladas três cepas de Listeria monocytogenes a partir de queijo tipo Ricota, obtidos de dois estabelecimentos, portanto em desacordo com os padrões contidos na Resolução n⿳o. 12 , que estipula a ausência deste microrganismo (ANVISA, 2001). Queijos como estes, com alto teor de umidade, são mais frequentemente relacionados com a presença desta espécie (FARBER \& PETERKIN, 1991). Dois destes isolados foram obtidos de um mesmo estabelecimento em períodos diferentes de coleta.

Tabela 2 - Resultados dos testes bioquímicos determinantes na identificação das Listeria spp., isoladas das amostras de queijos.

\begin{tabular}{|c|c|c|c|c|c|c|c|c|c|c|c|c|}
\hline 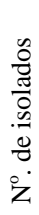 & 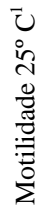 & 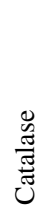 & 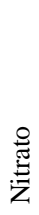 & $\sum_{>}^{N}$ & $\stackrel{m}{>}$ & 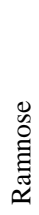 & 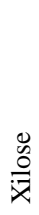 & 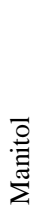 & 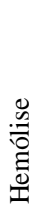 & 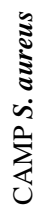 & 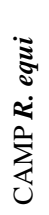 & 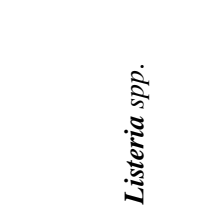 \\
\hline $5^{4}$ & + & + & - & + & + & + & - & - & - & - & - & L. innocua \\
\hline 1 & + & + & - & + & + & - & - & - & - & - & - & L. innocua \\
\hline 3 & + & + & - & + & + & + & - & - & + & + & - & L. monocytogenes \\
\hline 5 & + & + & - & + & + & - & + & - & + & + & - & L. seeligeri \\
\hline
\end{tabular}

${ }^{1}$ Motilidade característica de Listeria spp.; ${ }^{2}$ VM: Vermelho de Metila; ${ }^{3}$ VP: Voges Proskauer; ${ }^{4}$ Dois dos isolados foram recuperados após períodos diferentes de incubação (48 horas e 7 dias) da mesma amostra de queijo.

Ciência Rural, v.37, n.3, mai-jun, 2007. 
As outras espécies isoladas, $\mathbf{L}$. innocua e L. seeligeri, geralmente não são patogênicas, mas há um relato de infecção humana por L. seeligeri (MCLAUCHLIN et al., 2004). Segundo GASANOV et al. (2005), a presença de qualquer espécie de Listeria sp. pode ser um indicativo da presença de $\boldsymbol{L}$. monocytogenes ainda que esta não seja isolada. Isto pode ser explicado, parcialmente, pelo fato de esta espécie ser menos competitiva que as outras do seu gênero em qualquer meio de cultura, especialmente em presença de algumas substâncias seletivas ou na presença de altas contagens de microrganismos.

$\mathrm{O}$ pequeno número de amostras positivas para Listeria spp. não permitiu tratar estatisticamente os dados referentes à refrigeração. Entretanto, as três amostras, nas quais foram confirmadas a presença de L. monocytogenes, estavam estocadas sob refrigeração no momento da coleta. É característico dessa espécie o crescimento em temperaturas de refrigeração (GASANOV et al., 2005). Sete amostras positivas para Listeria spp. foram coletadas na primavera, 6 no outono e uma no verão. As estações do ano influenciaram no isolamento de Listeria spp. $(\mathrm{P}<0,05)$, sendo a primavera considerada a estação do ano com maior número de isolados e o verão com o menor. Tem sido demonstrado que a temperatura ambiental e mesmo a localização geográfica influenciam na deteç̧ão de Listeria spp. em queijos. Locais ou épocas com temperaturas mais amenas seriam mais propícias para multiplicação ou sobrevivência deste gênero (PIANTA et al., 2004).

Dos 14 isolados, 11 foram de amostras com LEB incubado durante dois dias, dois em LEB incubado durante sete dias e uma isolada do LEB sem incubação
(Tabela 3). Da análise dos resultados, verifica-se que a retirada de alíquotas a partir do meio de enriquecimento, após tempos diferentes de incubação, aumentam a probabilidade de detecção deste microrganismo, como já foi relatado anteriormente (MEIER \& TERPLAN, 1993).

Não foram isoladas Brucella spp. dos 80 queijos analisados. Freqüentemente, a presença de contagens elevadas de microrganismos competidores, como observado neste trabalho, pode dificultar o isolamento de patógenos de amostras de alimentos. Além disso, esses patógenos não sobrevivem por muito tempo em ambientes de $\mathrm{pH}$ ácido, característico de queijos (FAO-OMS, 1986). Metabólitos inibidores produzidos pela microbiota presente nas amostras provavelmente dificultaram o seu isolamento. Contudo, a presença de coliformes totais, fecais, de Listeria spp. indica que outros patógenos possam estar presentes nos queijos, incluindo a Brucella spp.

\section{CONCLUSÕES}

O consumo de queijos de fabricação artesanal constitui perigo de infecção à população em geral e, especialmente, àquelas pessoas imunocomprometidas. Medidas que visem à proteção da saúde da população e que auxiliem no crescimento econômico dos produtores devem ser implementadas enfocando o incentivo à produção de queijos através de cooperativas que adotem as boas normas de fabricação.

\section{AGRADECIMENTOS}

À Coordenação de Aperfeiçoamento de Pessoal de Nível superior (CAPES), pela concessão de bolsa de mestrado.

Tabela 3 - Espécies de Listeria sp. isoladas de queijos entre setembro de 2004 e junho de 2005 em estabelecimentos de beira de estrada no litoral norte do Rio Grande do Sul.

\begin{tabular}{|c|c|c|c|c|}
\hline Tipo queijo & $\mathrm{N}^{\mathrm{o}}$. queijos & armazenamento & tempo cultivo LEB* & Listeria sp. \\
\hline Colonial & 2 & Refrigerado & 48 horas & L. innocua \\
\hline Colonial & 1 & Refrigerado & 7 dias & L. innocua \\
\hline Ricota & 2 & Refrigerado & 48 horas & L. monocytogenes \\
\hline Ricota & 1 & Refrigerado & 7 dias & L. monocytogenes \\
\hline Colonial & 2 & Não-refrigerado & 48 horas & L. innocua \\
\hline Colonial & 1 & Não-refrigerado & 7 dias & L. innocua \\
\hline Colonial & 3 & Não-refrigerado & 48 horas & L. seeligeri \\
\hline Colonial & 1 & Não-refrigerado & s/incubação & L. seeligeri \\
\hline Provolone & 1 & Não-refrigerado & 48 horas & L. seeligeri \\
\hline
\end{tabular}

*: LEB: caldo de enriquecimento Listeria. 


\section{REFERÊNCIAS}

ALTON, G.G. et al. Techniques for the brucellosis laboratory. Paris - França: INRA, 1988. 190p.

ANVISA. Resolução - RDC No. 12, de 02 de janeiro de 2001. Ministério da Saúde, Agência Nacional de Vigilância Sanitária. Capturado em 06 dez. 2005. Online. Disponível na internet: http:e-legis.bvs.br/leisref/public/ showAct.php?id=144\&=PRINT_ VERSION (ed.). 35p.

ARAÚJO, W.N. et al. Determinação do nível de contaminação por coliformes totais no queijo Minas comercializado na Região Metropolitana de Salvador - Bahia. Revista Brasileira de Saúde e Produção Animal, Salvador, v.2, p.5-9, 2001.

COSSART, P. Listeria monocytogenes: un système modèle à l'interface génétique bactérienne et biologie cellulaire. Bulletin de la Société Française de Microbiologie, Paris, v.7, p.247250, 1992.

DATASUS. Morbidade Hospitalar do SUS - por local de internação - Internações por lista morbidade CID-10 e Unidades da Federação - Período: jan. 1984-out. 2005. 2005a. Capturado em 23 dez. 2005. Online. Disponível na internet: http://tabnet.datasus. gov.br/

DATASUS. Procedimentos hospitalares do SUS - por local de residência - Brasil - Internações por Unidade Federação segundo Procedimento - Listeriose. 2005b. Capturado em 29 dez. 2005. Online. Disponível na internet: http://tabnet.datasus.gov.br/cgi/tabcgi.exe?sih/cnv/ pruf.def

FAO - OMS. Comité Mixte FAO/OMS d'experts de la brucellose. Sixième rapport. Genève, Suissa: OMS, 1986. $145 p$.

FARBER, J.M.; PETERKIN, P.I. Listeria monocytogenes, a food borne pathogen. Microbiological Reviews, Ottawa, v.55, p.476-511, 1991

FEITOSA, T. et al. Pesquisa de Salmonella sp., Listeria sp. e microrganismos indicadores higiênico-sanitários em queijos produzidos no estado do Rio Grande do Norte. Ciência e Tecnologia de Alimentos, Campinas v.23, supl, p.162-165, 2003.

FERREIRA, C.R. et al. Espondilodiscite brucelósica: relato de caso. Revista da Sociedade Brasileira de Medicina Tropical, Uberaba, v.35, p.255-258, 2002.
FREITAS, J.A. et al. Isolamento de Brucella sp. em produtos de origem animal e significado em saúde pública. Revista de Ciências Agrárias, Belém, v.37, p.147-154, 2002.

GASANOV, U. et al. Methods for the isolation and identification of Listeria spp. and Listeria monocytogenes: a review. FEMS Microbiology Reviews, Amsterdam, v.29, p.851-875, 2005.

IDE, L.P.A.; BENEDET, H.D. Contribuição ao conhecimento do queijo colonial produzido na região serrana do estado de Santa Catarina, Brasil. Ciência e Agrotecnologia, Lavras, v.25, p.1351-1358, 2001.

LANGONI, H. et al. Isolation of Brucella spp from milk of brucellosis positive cows in São Paulo and Minas Gerais states. Brazilian Journal of Veterinary Research Animal Science, São Paulo, v.37, p.444-448, 2000.

LOGUERCIO, A.P.; ALEIXO, J.A.G. Microbiologia de queijo tipo minas frescal produzido artesanalmente. Ciência Rural, Santa Maria, v.31, p.1063-1067, 2001

MACFADDIN, J.F. Biochemical tests for identification of medical bacteria. 3.ed. Philadelphia: Lippincott Williams \& Wilkins, 2000. 912p.

MCLAUCHLIN, J. et al. Listeria monocytogenes and listeriosis: a review of hazard characterization for use in microbiological risk assessment of foods. International Journal of Food Microbiology, Londres, v.92, p.15-33, 2004.

MEIER, R.; TERPLAN, G. Investigation of cheese and other foodstuff samples with the Listeria-TEK ELISA. Letters in Applied Microbiology, Londres, v.17, p.97-100, 1993.

PIANTA, C. et al. Presença de Listeria sp. em queijo tipo colonial no Rio Grande do Sul. Veterinária em Foco, Canoas, v.2, p.5-14, 2004

SANTOS-NETO, L.L. et al. Abscesso esplênico por Brucella abortus. Revista da Sociedade Brasileira de Medicina Tropical, Uberaba, v.32, p.53-55, 1999.

SCHWAB, J.P.; EDELWEISS, M.I.A. Identificação imunohistoquímica de Listeria monocytogenes em placentas fixadas em formol e embebidas em parafina. Revista Brasileira de Ginecologia e Obstetrícia, Rio de Janeiro, v.25, p.501-505, 2003. 